\title{
Opinion and Special Articles: Amateur fundus photography with various new devices
}

\section{Our experience as neurology residents}

\author{
Saman Zafar, MD, Ylec Mariana Cardenas, MD, Lakshmi Leishangthem, MD, and Sridhara Yaddanapudi, MD \\ Neurology ${ }^{\circledR}$ 2018;90:897-901. doi:10.1212/WNL.0000000000005480
}

Correspondence

S. Zafar

zafarsam@einstein.edu

\begin{abstract}
Times are changing in the way we secure and share patient fundus photographs to enhance our diagnostic skills in neurology. At the recent American Academy of Neurology meeting, the use of a fundus camera and smartphones to secure good-quality fundus photographs of patients presenting with headache to the emergency department (ED) was presented. We were enthusiastic to replicate the success of the Fundus Photography vs Ophthalmoscopy Trial Outcomes in the Emergency Department (FOTO-ED) study in our neurology department, but encountered problems in terms of cost, setup, feasibility, and portability of the device. As neurology residents, we came up with 3 easier options. We present these 3 options as our personal experience, and hope to reignite enthusiasm among neurology trainees to find their own means of performing ophthalmoscopy routinely in the hospital, as it appears that the Internet market is now thriving with many other devices to make this examination easier and more rewarding. Of the options explored above, the Handheld Fundus Camera was a clear favorite among the residents, and we have placed one in our call room for routine use. It travels to the clinic, floor, intensive care unit, and ED when needed. It has enhanced the way we approach the fundus examination and been a fun skill to acquire. We look forward to further advances that will make it possible to carry such a device in a physician's pocket.
\end{abstract}

From Einstein Medical Center, Philadelphia, PA.

Go to Neurology.org/N for full disclosures. Funding information and disclosures deemed relevant by the authors, if any, are provided at the end of the article. 


\section{Glossary}

ED $=$ emergency department; FOTO-ED = Fundus Photography vs Ophthalmoscopy Trial Outcomes in the Emergency Department.

Ophthalmoscopy is a skill every neurology trainee must acquire. It is an essential part of the examination for various neurologic presentations, particularly headache and newonset visual symptoms. The routine use of ophthalmoscopy in stroke patients is to be encouraged: Fabry disease, Susac syndrome, and von Hippel-Lindau disease are a few among many uncommon causes of stroke in younger patients with diagnostic clues on ophthalmoscopy. Commonly encountered conditions may also be diagnosed with greater confidence with ophthalmoscopy - a recurring example is a hypertensive patient who is seen in the emergency department (ED) with new-onset blindness, with a neurology consultation placed to consider stroke-the visualization of bilateral papilledema and a subsequent diagnosis of hypertensive encephalopathy in such a case would make the need for an MRI seem less urgent.

Recent articles have highlighted the declining use of direct ophthalmoscopy among medical students and trainees. ${ }^{1,2}$ Apart from the time needed to acquire the technical skill to perform this test with confidence, we have, as neurology residents, all too frequently encountered patients who are photophobic and uncooperative with this examination: headache patients in EDs are a prime example of this situation. The reluctance to dilate pupils in EDs and on the neurology floor is a further hindrance to performing ophthalmoscopy reliably, as this interferes with subsequent examinations, particularly in critically ill patients. Indeed, we have found that ophthalmoscopy in the outpatient setting is less problematic and more rewarding that in the emergency or inpatient setting.

As we acknowledged this gap in our physical evaluation, we were enthusiastic to learn about the increasing use of low-cost fundus photography in neurology settings, ${ }^{3}$ and to hear Dr. Newman present her Fundus Photography vs Ophthalmoscopy Trial Outcomes in the Emergency Department (FOTO-ED) study at the 2017 American Academy of Neurology meeting, ${ }^{4}$ where she demonstrated the use of a fundus camera and smartphone to secure good-quality fundus photographs of patients presenting with headache to the ED. It appeared that a solution to our limitations in performing fundus examinations in the ED was apparent, and we set about trying to acquire the Kowa Alpha D Camera (Kowa Ophthalmic and Medical Equipment, Torrance, CA) for our neurology department. ${ }^{5}$ However, we encountered problems. The Kowa Camera was large, it would require a place to be stationed, and this would necessitate cooperation with the ED in training and use of the camera. The device was also expensive enough to require a formal grant to have it procured. Given these limitations, we explored more informal solutions, and came up with 3 options.
We present these 3 options as our personal experience, and hope it will spark enthusiasm among neurology trainees to find their own means of performing ophthalmoscopy routinely in the hospital, as it appears that the Internet market is thriving with many other devices to make this examination easier and more rewarding.

\section{Using the panoptic ophthalmoscope with an iPhone holder}

When the PanOptic Ophthalmoscope (Welch Allyn, Skaneateles Falls, NY) was introduced in 2001, it appeared to be the solution for clinicians who were struggling with the use of direct ophthalmoscopes with undilated pupils. ${ }^{6}$ The PanOptic Ophthalmoscope is easier to use than the direct ophthalmoscope. Our first experience with fundus photography was to secure a customized smartphone holder to use with the PanOptic, along with the Welch Allyn iExaminer Pro app. This enables an iPhone camera lens to show the image from the PanOptic directly onto the iPhone screen, and it is relatively easy to secure the image in the iExaminer app and send it to a secure hospital email address via the iPhone. We found it most useful for patients presenting with headache and vision loss to the ED (figure 1). For physicians who already use the PanOptic Ophthalmoscope, purchase of the smartphone holder is inexpensive and a straightforward way to capture images. Hence, affordability is an advantage of this technique.

Although this technique allows residents to document their ophthalmoscopy examination and share images with colleagues, it has limitations. Photophobic patients were not cooperative. The image quality was disappointing in most cases; there is a glare artifact that obscures some of the images and does not clear with repeated attempts at cleaning the lens. We have discussed this limitation with Welch Allyn; improvement in technique with experience may improve image quality. The skill of holding the PanOptic Ophthalmoscope in focus and pushing a button on the smartphone to activate image storing needs time to acquire. A recently popular YouTube video from Stanford University ${ }^{7}$ makes it appear relatively straightforward, and we agree that this is comfortably done in the clinic setting. However, we found this to be significantly more challenging in bedbound, uncooperative, or confused patients, which is a significant proportion of ED and floor patients.

\section{Using the Handheld Fundus Camera}

The market appears to be exploding with new products that claim to take high-quality fundus photographs with ease. Our department trialed the Handheld Fundus Camera (Digital Eye Center, Coral Gables, Florida). This device costs significantly more than the PanOptic Ophthalmoscope with its 

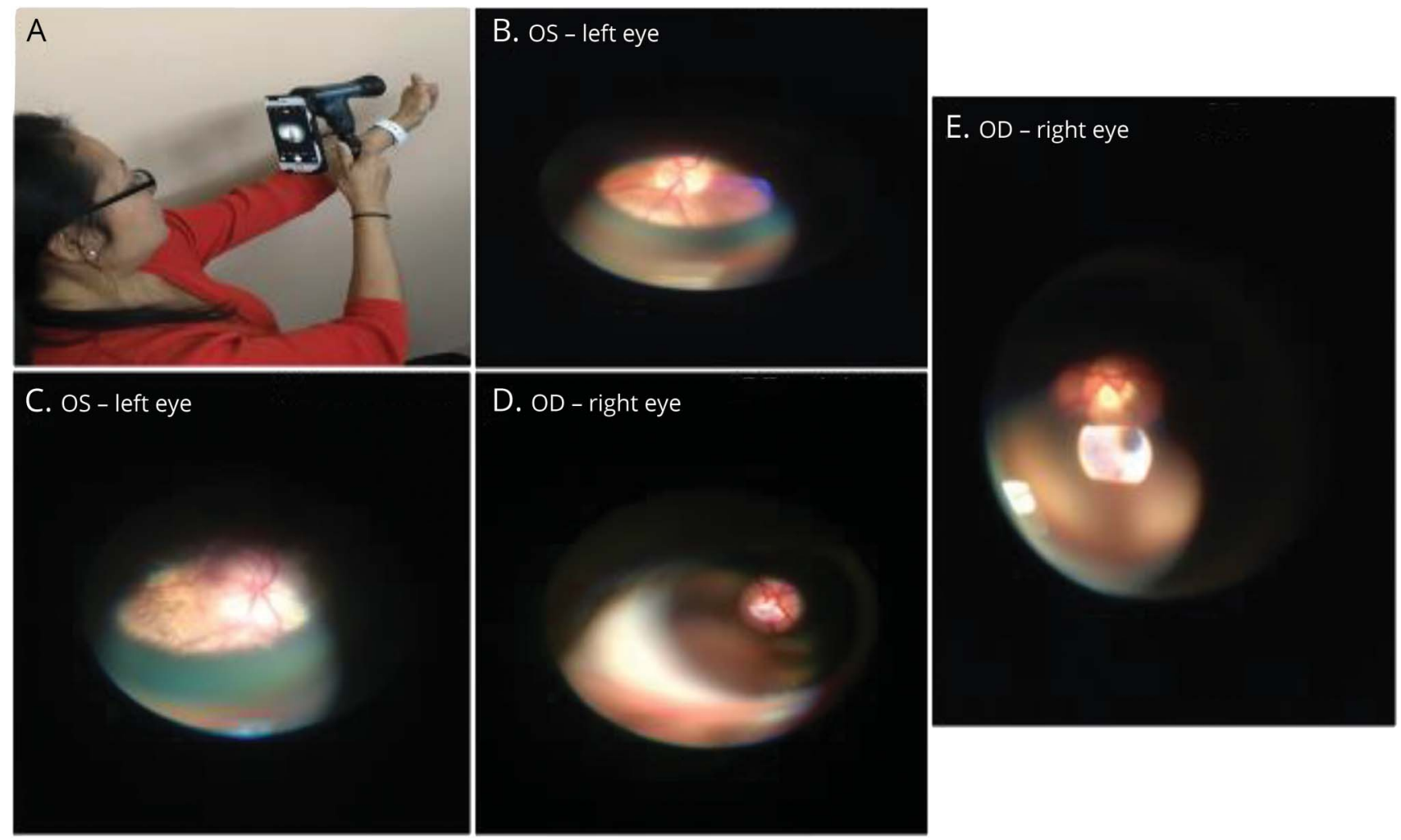

(A) Using the PanOptic Ophthalmoscope with an iPhone is relatively straightforward. (B) Using this technique in a patient previously known to have idiopathic intracranial hypertension with papilledema excluded papilledema and allowed us to determine her condition was improved. (C) Papilledema in a patient presenting with acute blindness/hypertensive emergency. (D) Normal optic disc in clinic patient with multiple sclerosis. Note glare artifact, which limits usefulness of image. (E) Normal optic disc of intensive care unit patient with brainstem herniation and brain death, leading to discussions that papilledema takes time to develop and is not always present in cases of acute increase in intracranial pressure.

smartphone holder, but is much lower in cost compared to the Kowa Alpha D Camera used in the FOTO-ED study, and also portable in a secure box to use all over the hospital. ${ }^{8}$ There is less patient discomfort with this device-the image of the fundus is focused on the camera screen without a need to shine light onto the retina-there is a momentary flash of light when the picture is actually taken. This device was easy to use; the neurology residents and medical students all managed to take high-quality fundus photographs within 10 minutes of using it. We had the support of our ophthalmology department in giving us a second opinion on the images we secured, and emailing the images to the ophthalmologist is straightforward. Figure 2 demonstrates how this helped us with the management of patients in clinic and on the floor.

\section{Using a smartphone with a 20-D lens: Indirect ophthalmoscopy}

This is the most inexpensive means of securing high-quality fundus photographs, but the most technically challenging of the 3 techniques. ${ }^{9}$ Our ophthalmology resident demonstrated how to use a 20-D lens with the light from a smartphone (iPhone 6; Apple, Cupertino, CA) in video mode to take an image of a dilated fundus in the ED (figure 3). Despite many attempts at duplicating her success, we were unsuccessful. This may be a skill we could acquire with more practice.

\section{Discussion}

Times are changing in the way we secure and share patient fundus photographs to enhance our diagnostic skills in neurology. We have sampled 3 methods of doing this, and are aware of many other devices on the market that can make routine fundus photography in neurology departments a routine practice. ${ }^{10-12}$

Of the options explored above, the Handheld Fundus Camera was a favorite among the residents, and we have placed one in our call room for routine use. It travels to the clinic, floor, intensive care unit, and ED when needed. It has enhanced the way we approach the fundus examination and been a fun skill to acquire. We look forward to further advances that will make it possible to carry such a device in a physician's pocket.

The 3 residents authoring this article all believed that direct ophthalmoscopy with pupillary dilation provides the best view and appreciation for ophthalmoscopy, and this remains a valuable skill to learn. We continue to use this in the 
Figure 2 Experience with the Handheld Fundus Camera from Digital Eye Solutions
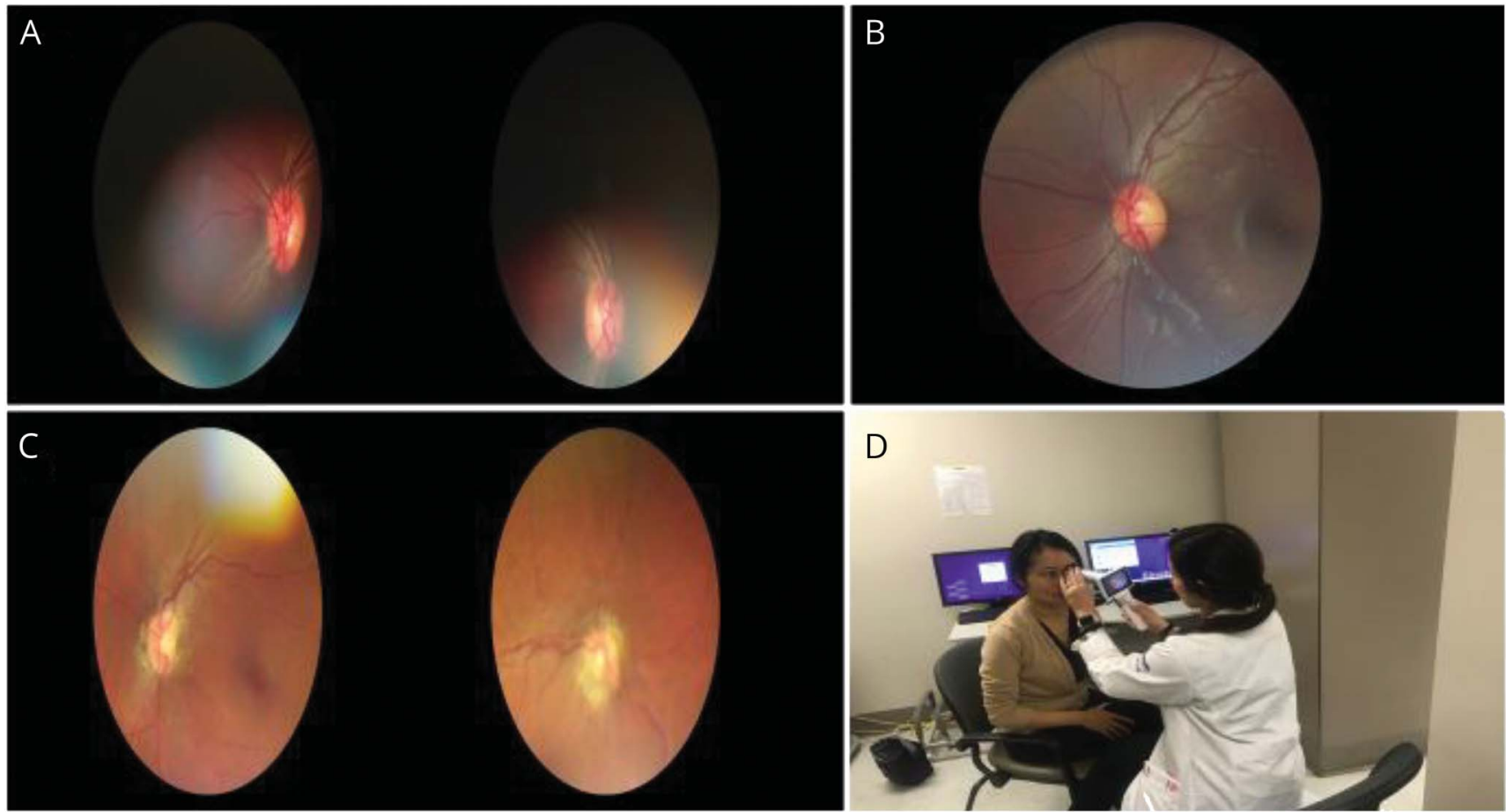

(A) Patient referred from outside hospital to neurology clinic with reported papilledema. He was asymptomatic. We were able to secure photographs and discuss his case with ophthalmology colleagues before reassuring the patient that he did not have papilledema. The urgency to pursue further investigations was reduced. (B) With minimal experience, the handheld camera could take fundus photographs or more panoramic views of the retina, as demonstrated here. (C) A patient with previous raised intracranial pressure, status post ventriculoperitoneal shunting, presented with headache and reported papilledema. After discussion with ophthalmology, we clarified that although the disc margins are not clear, the optic cup is well marked within the disc and there is no present papilledema; the findings may represent prior optic swelling that has resolved. This had important implications for the patient's subsequent management. (D) The handheld fundus camera we used is one of many available on the market, and was portable.

Figure 3 Smartphone/indirect ophthalmoscopy demonstrated by ophthalmology resident in the emergency department

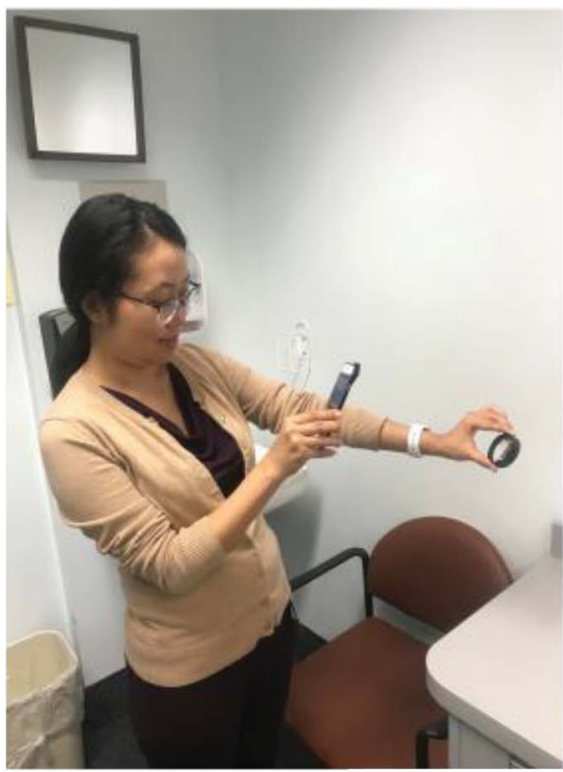

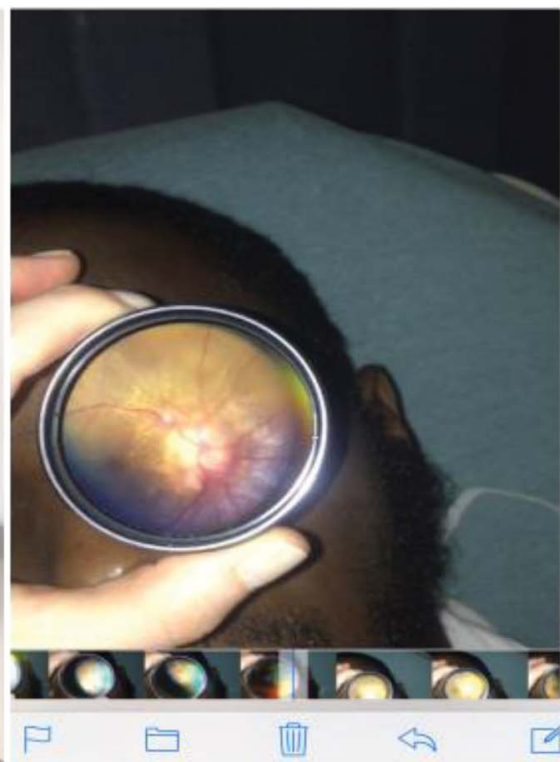

Using a smartphone in video mode (with flash on) and a 20-D lens on a dilated pupil, a clear image of the fundus was secured. Compared to the quality of the image for the same patient by the PanOptic Ophthalmoscope-smartphone combination (figure 1C), this technique provided a superior image. However, the neurology residents in our department did not find it easy to learn this technique. The ophthalmology resident agreed it takes time to learn. 
outpatient setting and with cooperative patients. However, with the availability of new technology, we find many situations where the use of these alternative devices plays a role. This article relays our personal experience, and is not meant to be a comparative analysis of the superiority of one method over another. Different institutions may derive different conclusions from their trials, and we hope the discussions generated by these experiences will lead to further discussions, as new devices become increasingly available and affordable.

\section{Author contributions}

Saman Zafar: preparing the article, taking images, trying the 3 fundus photograph techniques reported in this article. Lakshmi Leighanthem: preparing the article, taking images, trying the 3 fundus photograph techniques reported in this article. Ylec Mariana Cardena: preparing the article, taking images, trying the 3 fundus photograph techniques reported in this article. Sridhara Yaddanapudi: overseeing the use of fundus photography among the residents, liaising between neurology and ophthalmology.

\section{Study funding}

No targeted funding reported.

\section{Disclosure}

The authors report no disclosures relevant to the manuscript. Go to Neurology.org/N for full disclosures.

\section{References}

1. Mackay D, Garza PS, Beau B, Bruce B, et al. The demise of direct ophthalmoscopy: a modern clinical challenge. Neurol Clin Pract 2015;5:150-157.

2. Acierno M. Ophthalmoscopy for the neurologist. Neurologist 2001;7:234-251.

3. Mackay DD, Garza P. Ocular fundus photography as an educational tool. Semin Neurol 2015;35:496-505.

4. Nancy J. Newman, MD, receives prestigious lecture award from the American Academy of Neurology. Available at: eyecenter.emory.edu/press_releases/pr_faculty_60.htm Accessed December 20, 2017.

5. Lamirel C, Bruce B, Wright D, et al. Nonmydriatic digital ocular fundus photography on the iPhone 3G: the FOTO-ED study. Arch Ophthalmol 2012;130:939-940.

6. McComiskie JE, Greer RM, Gole GA. PanOptic versus conventional ophthalmoscope. Clin Exp Ophthalmol 2004;32:238-242.

7. Approach to funduscopy/ophthalmoscopy. Available at: youtu.be/NhzBjmlxAnk. Accessed December 20, 2017.

8. Portable Fundus Camera Digital FC-40-2 mpx: Manual Focus. Available at: www.digitaleyecenter.com/product/portable-fundus-camera-digital/. Accessed December 20, 2017.

9. Haddock LJ, Kim DY, Mukai S. Simple, inexpensive technique for high-quality smartphone fundus photography in human and animal eyes. J Ophthalmol 2013; 2013:518479.

10. Schiffman RM, Jacobsen G, Nussbaum JJ, et al. Comparison of a digital retinal imaging system and seven-field stereo color fundus photography to detect diabetic retinopathy in the primary care environment. Ophthalmic Surg Lasers Imaging 2005;36:46-56.

11. Panwar N, Huang P, Lee J, et al. Fundus photography in the 21 st century: a review of recent technological advances and their implications for worldwide healthcare. Telemed J E Health 2016;22:198-208.

12. Shanmugam MP, Mishra D, Madhukumar R, et al. Fundus imaging with a mobile phone: a review of techniques. Indian J Ophthalmol 2014;62:960-962.

\section{Did You Know...}

...you can browse by subspecialty topics on Neurology.org?

Go to: Neurology.org and click on "Topics" in the top navigation bar.

\section{Register for July Sports Concussion Conference in Indianapolis}

Secure your hotel and take advantage of early registration savings for the 2018 AAN Sports Concussion Conference this July 20 through 22 at the JW Marriott in Indianapolis, IN. The early registration deadline is June 14.

New this year:

- Joint programming with the NCAA including a Networking Reception at the NCAA Hall of Champions and talks focusing on the NCAA-DoD CARE Consortium

- Working Lunch with Experts who will address controversial issues in sports

- A Year in Review featuring the latest updates in concussion research and clinical guidance

- Unique and interactive "What Do I Do Now?" sessions where faculty will share challenging real-life cases and attendees will be invited to weigh in on best practices

Visit AAN.com/view/ConcussionConference 


\section{Neurology}

Opinion and Special Articles: Amateur fundus photography with various new devices:
Our experience as neurology residents

Saman Zafar, Ylec Mariana Cardenas, Lakshmi Leishangthem, et al.

Neurology 2018;90;897-901

DOI 10.1212/WNL.0000000000005480

This information is current as of May 7, 2018

\section{Updated Information \&} Services

References

Subspecialty Collections

Permissions \& Licensing

Reprints including high resolution figures, can be found at: http://n.neurology.org/content/90/19/897.full

This article cites 9 articles, 1 of which you can access for free at: http://n.neurology.org/content/90/19/897.full\#ref-list-1

This article, along with others on similar topics, appears in the following collection(s):

All Headache

http://n.neurology.org/cgi/collection/all_headache

Clinical neurology examination

http://n.neurology.org/cgi/collection/clinical_neurology_examination

Information about reproducing this article in parts (figures,tables) or in its entirety can be found online at:

http://www.neurology.org/about/about_the_journal\#permissions

Information about ordering reprints can be found online:

http://n.neurology.org/subscribers/advertise

Neurology ${ }^{\circledR}$ is the official journal of the American Academy of Neurology. Published continuously since 1951, it is now a weekly with 48 issues per year. Copyright @ 2018 American Academy of Neurology. All rights reserved. Print ISSN: 0028-3878. Online ISSN: 1526-632X.

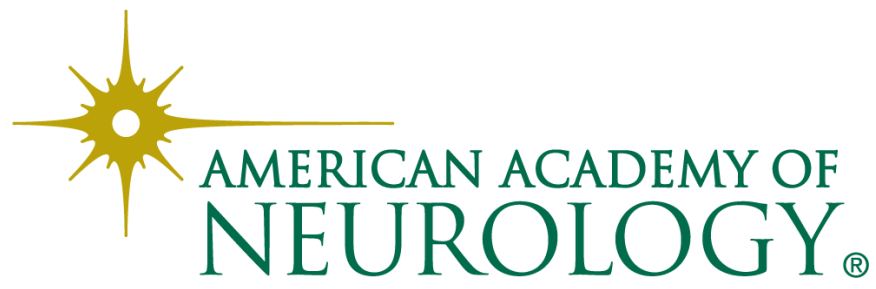

